\title{
REALIZATION OF THE PRIMARY TERRESTRIAL REFERENCE FRAME
}

\author{
W. KOSEK, B. KOLACZEK \\ Space Research Centre, Polish Academy of Sciences \\ Bartycka 18, 00-716 Warsaw, Poland
}

\begin{abstract}
The PTRF is based on 43 sites with 64 SSC collocation points with the optimum geographic distribution, which were selected from all stations of the ITRF89 according to the criterion of the minimum value of the errors of 7 parameters of transformation. The ITRF89 was computed by the IERS Terrestrial Frame Section in Institut Geographique National - IGN and contains 192 VLBI and SLR stations (points) with 119 collocation ones. The PTRF has been compared with the ITRF89. The errors of the 7 parameters of transformation between the PTRF and 18 individual SSC as well as the mean square errors of station coordinates are of the same order as those for the ITRF89. The transformation parameters between the ITRF 89 and the PTRF are negligible and their errors are of the order of $3 \mathrm{~mm}$.
\end{abstract}

\section{Introduction}

Geodetic and geodynamic investigations on the level of subcentimeter accuracy are the goals of the next decade. A well defined and stable terrestrial reference frame is needed for these purposes (Mueller et al., 1989).

The IERS Terrestrial Reference Frames ITRF88, ITRF89 (Boucher, 1988; Boucher et al. 1989; IERS, 1989-1990) are the best combine solutions developed from previous BIH Terrestrial Systems - BTS 1984 - BTS 1987 (BIH; 1986-1989; Boucher et al., 1984, 1985, 1986, 1988). The ITRF89 is defined by 192 VLBI, SLR and LLR stations which coordinates were computed as a combination of 18 Sets of Station Coordinates - SSC (IERS, 1990).

The accuracy of the transformation parameters between the individual SSC and the ITRF89 is now of the order of 1 to $10 \mathrm{~cm}$, and depends on the number, the distribution and the accuracy of collocation stations in each SSC. The accuracy of the ITRF89, defined by the accuracy of 7 parameters of transformation depends mostly on distribution of the SSC collocation stations. The ITRF89 stations are located mostly in Western Europe and North America. The most number of such stations, which are not located homogeneously all over the Earth do not improve the accuracy of the ITRF89. A terrestrial reference frame can be defined with the same accuracy by smaller number of stations with accurate coordinates and optimum geographic distribution (Kosek et al., 1990). In the paper the choice of the optimum number and geographic distribution of stations taken from the ITRF89 set of stations was done and new terrestrial reference frame named the Primary Terrestrial Reference Frame - PTRF was determined. The PTRF consisted of 64 SSC collocation points with a good distribution and accuracy of their coordinates is presented as a combination of 18 Sets of Station Coordinates. Such system can be used in geodynamic investigations and for other global geodetic activities. The ITRF with larger number of stations with 
coordinates in the PTRF system can be used for all other purposes.

\section{Method of analysis}

The sites of the PTRF with the optimum geographic distribution were selected from the ITRF89 stations according to the criterion of the minimum value of the errors of 7 parameters of transformations obtained by the least-squares adjustment.

The observational equation for the least-squares adjustment written for the $i-t h$ station is given by the following formula:

$$
\left(\begin{array}{l}
X_{k} \\
Y_{k} \\
Z_{k}
\end{array}\right)=\left(\begin{array}{l}
X_{i} \\
Y_{i} \\
Z_{i}
\end{array}\right)-\left(\begin{array}{l}
T_{1} \\
T_{2} \\
T_{3}
\end{array}\right)-\left(\begin{array}{ccc}
D & -R 3 & R 2 \\
R 3 & D & -R 1 \\
-R 2 & R 1 & D
\end{array}\right)\left(\begin{array}{l}
X_{i} \\
Y_{i} \\
Z_{i}
\end{array}\right)
$$

where: $X_{k}, Y_{k}, Z_{k}$ are disturbed by the white noise station coordinates $X_{i}, Y_{i}, Z_{i}$,

$T_{1}, T_{2}, T_{3}$ are the translation parameters,

$D$ is the excess to 1 of the scale factor,

$R 1, R 2, R 3$ are the small Euler rotation angles.

The equation (1) have been weighted by dividing it by the mean square error of a station computed from the mean square errors of station coordinates given in the ITRF89 solution:

$$
m_{i}=\sqrt{\left(m_{x_{i}}^{2}+m_{y_{i}}^{2}+m_{z_{i}}^{2}\right)},
$$

The errors of 7 parameters of transformation are given by the following formula:

$$
m_{j}=m_{\circ} \sqrt{\left(A^{T} A\right)_{j j}^{-1}} \quad, \text { for } j=1,2, \ldots, 7
$$

$A$ is the $t \times l$ matrix of the observational equation coefficients with $t=7$ and $l=3 N$, $N$ is the number of stations.

In this equation the errors of the parameters of transformation depend only on the values of the diagonal elements of the matrix $\left(A^{T} A\right)^{-1}$ since the value of $m_{o}$ is constant for the same number of stations. These diagonal elements depend on the stations distribution as well as on the $m_{i}$ errors.

First the points of the highest accuracy of coordinates have been chosen in each site. Next the stations of not good distribution and accuracy have been eliminated sequentially according to the criterion of the minimum value of the errors of 7 parameters of transformation. These errors are minimum when the trace of the variance covariance matrix has a minimum value $\left(\operatorname{tr}\left(A^{T} A\right)^{-1}=\min \right)$. In order to choose the optimum distribution of $N-1$ stations from the set of $N$ the $\left(\begin{array}{c}N \\ N-1\end{array}\right)$ combinations were analysed. From $N$ number of stations a number of $N-1$ such stations were selected, for which the value of $\operatorname{tr}\left(A^{T} A\right)^{-1}=\min$. It enables elimination of one station and after that the number of $N-2$ stations from $N-1$ stations can be selected. All collocation stations of VLBI and SLR or LLR instruments have been included in the computation of the PTRF in order to get better tie of the VLBI to SLR systems, though for some of them like METSAHOVI, FLAGSTAFF, PASADENA, YUMA, PLATTEVILLE and SAN DIEGO the trace matrix analysis show that they ought to be eliminated.

Additionally points like: GOLDSTONE (S009, S014, S019), FORT DAVIS (M006), CANBERRA (S003) and MADRID (S001, S010) were also included to the computation in 
order to get the solution for the transformation parameters for each SSC for which at least 3 stations are necessary. All the SSC collocation stations of the Southern hemisphere are important for the computation of the PTRF, because of the small number of stations in this hemisphere. The improvement of the accuracy of their coordinates is very important for the better definition of the Terrestrial Reference Frame and the PTRF.

Finally, the PTRF consisting of 43 sites with 64 SSC collocation points was computed (Fig. 1). Using the least squares adjustment and the IGN program for ITRF computation (Boucher et al., 1988, 1989) the coordinates $X_{i}, Y_{i}, Z_{i}$, of the PTRF as well as the transformation parameters: $T_{1}, T_{2}, T_{3}, D, R 1, R 2, R 3$, between this frame and the individual SSC were obtained (Tab. 1.) on the base of formula (1). The scale and the origin of the SSC-CSR89L02 have been adopted for definition of the ITRF88, ITRF89 and the PTRF systems and they were held fixed in the adjustment of the PTRF. The orientation of the PTRF axes is adopted to be the same as in the ITRF88 and ITRF89 systems and differs about fixed rotation angles from the SSC-CSR89L02 system. The transformation parameters from the PTRF to the individual SSC's are in a very good agreement with the transformation parameters from ITRF89 to the same individual SSC's (Tab. 1.,2.). The differences are smaller than their RMS errors except for such SSC like: GAOUA90L01 $\left(T_{2}\right)$ and LPAC90L01 $\left(T_{2}, D\right)$. The errors of these transformation parameters are of the same order as for the ITRF89. The errors of the coordinates of the PTRF stations (Tab. 3.) and the $\sigma_{0}=1.35 \mathrm{~cm}$ are of the same order as for the ITRF89 $\left(\sigma_{0}=1.34 \mathrm{~cm}\right)$.

The transformation parameters from the PTRF to ITRF89 reference frames are negligible (Tab. 1.) and their RMS are of the order of $3 \mathrm{~mm}$.

\section{Conclusions}

The PTRF consisting of 64 SSC collocation points in 43 sets carefully chosen defines the terrestrial system as well as the ITRF89 consisting of 119 SSC collocation points. About half a number of SSC collocation points due to not homogeneous distribution and lower coordinate accuracy have no influence on the accuracy of determination of the ITRF89. More number of the eliminated collocation station are located in Europe and North America. The PTRF defines well an ITRF for global geodynamic investigations. The ITRF with larger number of stations is useful for other geodetic activities.

\section{Acknowledgements}

The computation was made during the visit of Mr. W. Kosek at the Institut Geographique National due to kind invitation of Dr. C. Boucher. Mr. W. Kosek thanks Dr. Z. Altamimi for his kind assistance in the use of the IGN software for ITRF determination. 


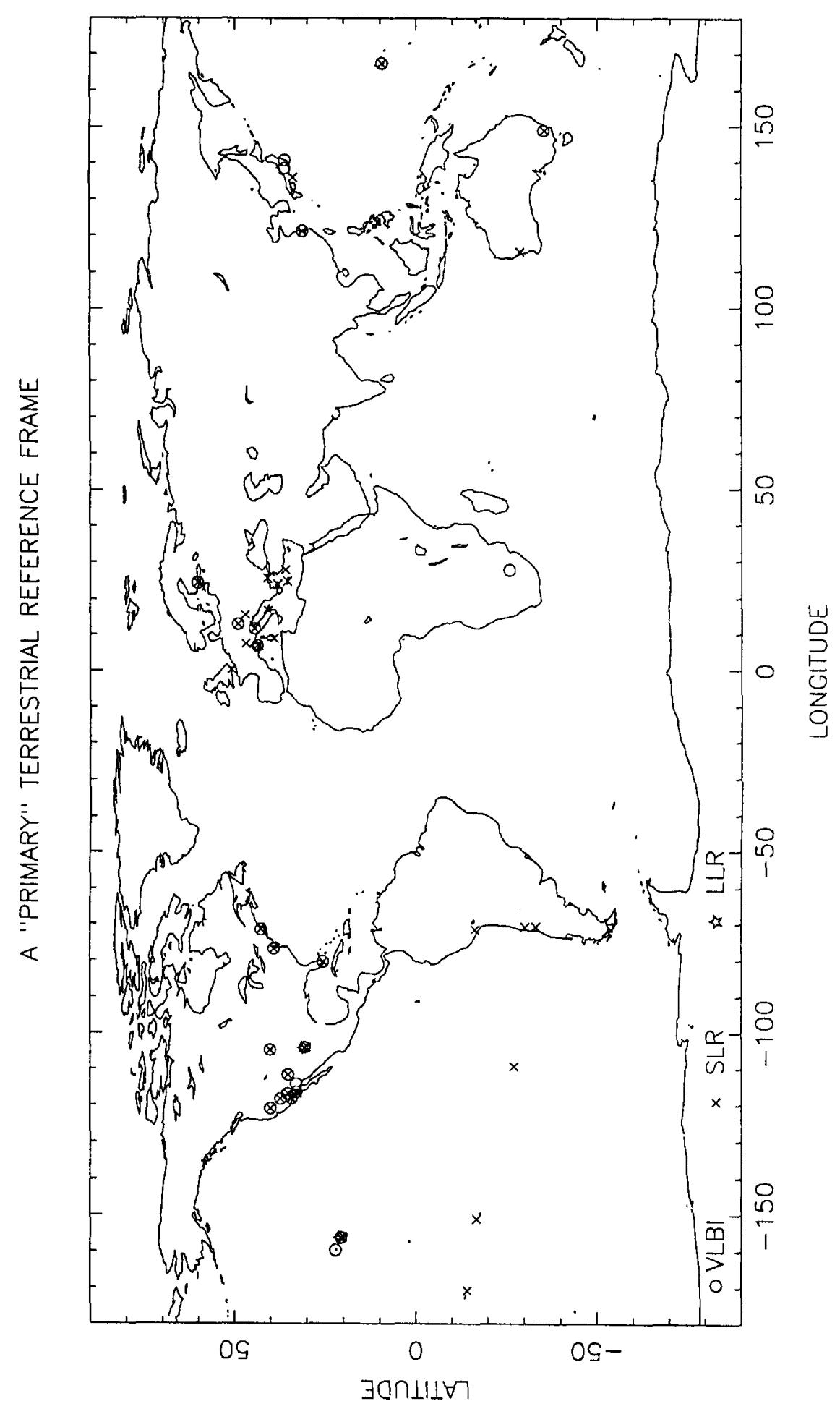


Table 1. Transformation parameters from the Primary Terrestrial Reference Frame to individual SSC systems and to the ITRF89 at epoch 1988.0.

\begin{tabular}{|c|c|c|c|c|c|c|c|c|c|}
\hline SSC & $\mathrm{T} 1$ & $\begin{array}{r}\mathrm{T} 2 \\
{[\mathrm{~cm}]}\end{array}$ & T3 & $\begin{array}{r}\mathrm{D} \\
10^{-8}\end{array}$ & $\mathrm{R} 1$ & $\begin{array}{r}\mathrm{R} 2 \\
{[\mathrm{mas}]}\end{array}$ & R3 & \multicolumn{2}{|c|}{ Coll. stations } \\
\hline \multirow[t]{2}{*}{ GSFC 90R02 } & 161.4 & -86.0 & 52.0 & -0.7 & 2.1 & 1.5 & 0.2 & \multirow[t]{2}{*}{21} & \multirow[t]{2}{*}{15} \\
\hline & 1.1 & 1.2 & 1.1 & 0.2 & 0.5 & 0.4 & 0.4 & & \\
\hline \multirow[t]{2}{*}{ NGS 90R01 } & -0.2 & -4.7 & 5.1 & -0.3 & -3.8 & 10.5 & -0.2 & \multirow[t]{2}{*}{14} & \multirow[t]{2}{*}{12} \\
\hline & 1.2 & 1.2 & 1.2 & 0.2 & 0.5 & 0.5 & 0.4 & & \\
\hline \multirow[t]{2}{*}{ USNO 90R01 } & -8.5 & -16.5 & 3.5 & -1.8 & -0.4 & 2.2 & 0.5 & \multirow[t]{2}{*}{4} & \multirow[t]{2}{*}{4} \\
\hline & 2.0 & 2.4 & 2.3 & 0.3 & 1.1 & 0.8 & 0.6 & & \\
\hline \multirow[t]{2}{*}{ SO 88R01 } & 162.8 & -107.3 & 36.9 & -0.5 & -7.4 & 7.0 & -2.0 & \multirow[t]{2}{*}{3} & \multirow[t]{2}{*}{2} \\
\hline & 7.8 & 4.7 & 6.4 & 0.5 & 2.5 & 3.4 & 1.4 & & \\
\hline \multirow{2}{*}{ NAOMZ 89R01 } & -10.1 & 13.3 & -4.2 & 1.3 & -4.1 & 9.1 & -1.4 & \multirow[t]{2}{*}{3} & \multirow[t]{2}{*}{3} \\
\hline & 9.0 & 8.6 & 7.5 & 1.2 & 3.3 & 3.5 & 2.5 & & \\
\hline \multirow[t]{2}{*}{ JPL 90R02 } & -0.2 & -4.6 & 9.1 & -3.1 & 2.3 & 1.6 & 0.1 & \multirow[t]{2}{*}{3} & \multirow[t]{2}{*}{2} \\
\hline & 2.7 & 2.9 & 2.8 & 0.4 & 1.4 & 1.2 & 1.5 & & \\
\hline \multirow[t]{2}{*}{ CSR 89L02 } & 0.0 & 0.0 & 0.0 & 0.0 & -3.4 & 4.3 & -15.9 & \multirow[t]{2}{*}{46} & \multirow[t]{2}{*}{37} \\
\hline & - & - & - & - & - & - & - & & \\
\hline \multirow{2}{*}{ GSFC 89L01 } & -2.0 & -0.7 & 1.7 & 0.1 & -0.7 & 5.2 & -7.5 & \multirow[t]{2}{*}{40} & 35 \\
\hline & 1.1 & 1.1 & 1.0 & 0.2 & 0.4 & 0.4 & 0.4 & & \\
\hline DGFII 89L03 & 0.4 & -0.3 & 4.6 & -0.2 & -286.1 & -46.0 & 3.4 & 18 & 4 \\
\hline & 1.5 & 1.5 & 1.4 & 0.2 & 0.6 & 0.6 & 0.5 & & \\
\hline DUT 90LO1 & -0.4 & -1.2 & -5.9 & -1.1 & 0.1 & 1.7 & -4.3 & 22 & 9 \\
\hline & 1.3 & 1.3 & 1.3 & 0.2 & 0.5 & 0.5 & 0.5 & & \\
\hline ZIPE 90L01 & -1.8 & 0.5 & -8.0 & 0.1 & 0.5 & 0.8 & 0.6 & 29 & 9 \\
\hline & 1.3 & 1.3 & 1.2 & 0.2 & 0.5 & 0.5 & 0.4 & & \\
\hline S0 90L01 & -0.5 & 0.5 & 1.1 & -0.6 & -3.7 & 5.2 & -14.3 & 30 & 12 \\
\hline & 1.3 & 1.3 & 1.2 & 0.2 & 0.5 & 0.5 & 0.4 & & \\
\hline GAOUA 90L01 & -2.0 & 0.4 & -0.6 & -1.0 & 1.1 & 2.6 & -0.8 & 26 & 14 \\
\hline & 1.4 & 1.3 & 1.3 & 0.2 & 0.5 & 0.5 & 0.4 & & \\
\hline LPAC 90L01 & 0.8 & 1.9 & 8.9 & -0.6 & 2.2 & -0.1 & -4.2 & 20 & 7 \\
\hline & 1.7 & 1.6 & 1.6 & 0.2 & 0.6 & 0.7 & 0.6 & & \\
\hline UTXMO 90M01 & -2.4 & -0.7 & 34.3 & -4.2 & -0.8 & 0.2 & -3.1 & 6 & 0 \\
\hline & 5.9 & 7.7 & 5.4 & 1.0 & 2.4 & 1.7 & 3.3 & & \\
\hline JPL 90M01 & -9.8 & -1.8 & 0.4 & -2.0 & 1.5 & 3.2 & -1.4 & 6 & 0 \\
\hline & 4.5 & 5.0 & 4.7 & 0.6 & 2.3 & 1.7 & 1.3 & & \\
\hline CERGA 89M01 & -13.2 & 3.6 & -4.7 & -5.3 & 0.6 & 3.5 & -11.5 & 5 & 0 \\
\hline & 4.6 & 5.3 & 4.8 & 0.6 & 2.5 & 1.7 & 1.3 & & \\
\hline S0 86M01 & -17.2 & 21.8 & 6.8 & -1.8 & 16.0 & 6.9 & -6.1 & 4 & 0 \\
\hline & 9.1 & 10.5 & 9.5 & 1.2 & 5.0 & 3.5 & 2.6 & & \\
\hline ITRF89 & -0.1 & -0.6 & -0.1 & 0.0 & -0.1 & 0.0 & 0.0 & 64 & 55 \\
\hline & 0.3 & 0.3 & 0.3 & 0.1 & 0.1 & 0.1 & 0.1 & & \\
\hline
\end{tabular}


Table 2. Differences between transformation parameters from the PTRF to the individual SSC systems and from the ITRF89 to the individual SSC systems.

\begin{tabular}{|r|rrrrrrr|}
\hline SSC & T1 & $\begin{array}{r}\text { T2 } \\
{[\mathrm{cm}]}\end{array}$ & T3 & $\begin{array}{c}\mathrm{D} \\
10^{-8}\end{array}$ & $\mathrm{R} 1$ & $\begin{array}{c}\mathrm{R} 2 \\
{[\mathrm{mas}]}\end{array}$ & $\mathrm{R} 3$ \\
\hline GSFC 90R02 & 0.2 & 1.0 & 0.1 & 0.1 & 0.3 & -0.2 & 0.0 \\
NGS 90R01 & 0.0 & 0.6 & 0.3 & 0.0 & 0.1 & -0.1 & 0.2 \\
USNO 90R01 & -0.6 & 0.5 & -1.8 & 0.0 & -0.4 & 0.3 & 0.4 \\
SO 88R01 & 1.6 & -0.5 & -0.2 & 0.1 & -0.2 & -0.5 & -0.4 \\
NAOMZ 89R01 & -2.3 & 1.5 & 1.2 & 0.1 & -0.2 & 1.1 & 0.1 \\
JPL 90R02 & 1.5 & -0.8 & 2.2 & 0.5 & 0.1 & -0.2 & 0.2 \\
CSR 89L02 & 0.0 & 0.0 & 0.0 & 0.0 & 0.0 & 0.0 & 0.0 \\
GSFC 89L01 & -1.0 & 0.3 & -0.7 & 0.1 & 0.3 & -0.1 & 0.2 \\
DGFII 89L03 & 0.4 & 0.7 & 0.2 & 0.0 & 0.2 & 0.0 & 0.0 \\
DUT 90LO1 & 0.1 & 1.1 & 0.2 & 0.0 & 0.1 & 0.0 & 0.1 \\
ZIPE 90L01 & 1.3 & 0.1 & 0.6 & 0.0 & 0.2 & -0.2 & -0.1 \\
S0 90L01 & 0.1 & 1.2 & -0.6 & 0.2 & -0.2 & 0.2 & -0.1 \\
GAOUA 90L01 & 1.3 & 2.2 & 1.1 & 0.2 & 0.3 & -0.6 & 0.0 \\
LPAC 90L01 & -0.7 & 2.8 & 0.0 & -0.4 & -0.1 & 0.6 & 0.5 \\
UTXMO 90M01 & 0.2 & 1.3 & 0.1 & 0.1 & 0.1 & -0.1 & 0.0 \\
JPL 90M01 & 0.2 & 1.0 & 0.2 & 0.0 & 0.1 & -0.1 & 0.0 \\
CERGA 89M01 & 0.2 & 1.0 & 0.1 & 0.0 & 0.1 & -0.1 & 0.0 \\
S0 86M01 & 0.2 & 1.0 & 0.1 & 0.1 & 0.1 & -0.1 & 0.1 \\
\hline
\end{tabular}

Table 3. The station coordinates of the Primary Terrestrial Reference Frame.

\begin{tabular}{|c|c|c|c|c|c|c|c|}
\hline & STATION & $X$ & $m_{x}$ & $\begin{array}{l}Y_{[\mathrm{m}]} \\
\end{array}$ & $m_{y}$ & $Z$ & $m_{z}$ \\
\hline$\underline{\text { S010 }}$ & CANBERRA & -4460935.076 & .022 & 2682765.771 & .021 & -3674381.711 & .021 \\
\hline S010 & MADRID-R & 4849336.797 & .019 & -360488.893 & .019 & 4114748.621 & .020 \\
\hline S014 & GOLDSTON & -2351129.050 & .015 & -4655477.095 & .015 & 3660956.884 & .015 \\
\hline M102 & WASHINGT & 1130686.678 & .011 & -4831353.025 & .011 & 3994110.875 & .011 \\
\hline$\underline{\mathrm{M} 002}$ & MAUI I & -5465998.456 & .012 & -2404408.544 & .012 & 2242228.403 & .013 \\
\hline$\underline{S 001}$ & JOHANNES & 5085442.829 & .024 & 2668263.391 & .025 & -2768697.273 & .024 \\
\hline$\overline{\mathrm{S} 002}$ & WESTFORD & 1492404.925 & .012 & -4457266.488 & .012 & 4296881.692 & .013 \\
\hline$\underline{5003}$ & FORT DAV & -1324210.866 & .010 & -5332023.144 & .011 & 3232118.375 & .011 \\
\hline S001 & KASHIMA & -3997892.273 & .020 & 3276581.312 & .019 & 3724118.288 & .022 \\
\hline$\underline{\mathrm{S} 001}$ & KAUAI & -5543845.987 & .014 & -2054564.165 & .013 & 2387813.766 & .013 \\
\hline$\underline{\mathrm{S} 003}$ & KWAJALEI & -6143536.502 & .017 & 1363997.208 & .017 & 1034707.353 & .019 \\
\hline S001 & BOLOGNE & 4461370.198 & .016 & 919596.751 & .017 & 4449559.046 & .018 \\
\hline$\underline{\mathrm{M} 013}$ & GOLDSTON & -2356494.019 & .011 & -4646607.672 & .012 & 3668426.599 & .012 \\
\hline $\mathbf{S 0 0 9}$ & GOLDSTON & -2356170.906 & .011 & -4646755.885 & .011 & 3668470.584 & .011 \\
\hline$\underline{\mathrm{M} 003}$ & MONUMENT & -2386289.312 & .011 & -4802346.566 & .012 & 3444883.962 & .012 \\
\hline M004 & OWENS VA & -2410421.134 & .013 & -4477800.428 & .013 & 3838690.309 & .013 \\
\hline$\overline{\mathrm{M002}}$ & PLATTEVI & -1240708.017 & .013 & -4720454.337 & .013 & 4094481.633 & .013 \\
\hline$\underline{S 001}$ & RICHMOND & 961258.174 & .013 & -5674090.035 & .013 & 2740533.732 & .014 \\
\hline S009 & SHANGHAI & -2831686.666 & .018 & 4675733.885 & .018 & 3275327.806 & .020 \\
\hline S004 & WETTZELL & 4075540.093 & .014 & 931735.168 & .014 & 4801629.244 & .014 \\
\hline
\end{tabular}


Table 3. cont.

\begin{tabular}{|c|c|c|c|c|c|c|c|}
\hline & STATION & $X$ & $m_{x}$ & $\begin{array}{l}Y \\
{[\mathrm{~m}]}\end{array}$ & $m_{y}$ & $\bar{Z}$ & $m_{z}$ \\
\hline M001 & YUMA & -2196777.811 & .018 & -4887337.065 & .018 & 3448425.231 & .018 \\
\hline$\underline{\mathbf{S 0 0 1}}$ & MADRID-R & 4849092.729 & .067 & -360180.596 & .068 & 4115108.964 & .070 \\
\hline Mo03 & SAN DIEG & -2428826.596 & .012 & -4799754.325 & .015 & 3417267.044 & .015 \\
\hline$\underline{\mathrm{M} 006}$ & FORT DAV & -1330020.936 & .010 & -5328401.851 & .012 & 3236480.796 & .011 \\
\hline M001 & FORT DAV & -1330125.263 & .010 & -5328526.640 & .011 & 3236150.244 & .011 \\
\hline$\underline{\text { M001 }}$ & YARRAGAD & -2389006.532 & .020 & 5043329.288 & .019 & -3078525.383 & .020 \\
\hline M001 & WESTFORD & 1492453.790 & .012 & -4457278.752 & .012 & 4296815.886 & .013 \\
\hline M001 & KWAJALEI & -6143447.268 & .018 & 1364700.185 & .017 & 1034163.112 & .019 \\
\hline M001 & SAMOA & -6100045.855 & .029 & -996203.144 & .029 & -1568976.327 & .029 \\
\hline$\underline{\mathrm{M} 002}$ & EASTER I & -1884984.374 & .021 & -5357608.169 & .020 & -2892853.406 & .020 \\
\hline$\underline{\mathrm{M} 105}$ & WASHINGT & 1130719.790 & .011 & -4831350.573 & .011 & 3994106.477 & .011 \\
\hline M002 & QUINCY & -2517234.690 & .013 & -4198556.250 & .013 & 4076569.654 & .013 \\
\hline M001 & MONUMENT & -2386277.917 & .011 & -4802354.367 & .012 & 881.438 & .012 \\
\hline$\underline{\mathrm{M} 001}$ & PLATTEVI & -1240678.122 & .013 & -4720463.373 & .013 & 480.608 & .013 \\
\hline$\underline{\text { M001 }}$ & OWENS VA & -2410422.357 & .013 & -4477802.689 & .013 & 3838686.692 & .013 \\
\hline$\underline{\mathrm{M} 002}$ & GOLDSTON & -2350861.547 & .015 & -4655546.275 & .015 & 3660997.827 & .015 \\
\hline$\underline{\mathrm{M} 003}$ & HUAHINE & -5345865.399 & .025 & 8246.717 & .025 & 623.889 & .025 \\
\hline$\underline{\mathrm{M} 001}$ & MAUI I & -5466006.470 & .012 & -2404427.953 & .012 & 2187.475 & .013 \\
\hline$\underline{\mathrm{M} 002}$ & RICHMOND & 961319.050 & .013 & -5674090.966 & .013 & 2740489.520 & .014 \\
\hline M001 & SANTIAGO & 1769699.798 & .029 & -5044612.926 & .030 & 8260.050 & .029 \\
\hline$\underline{\mathrm{M} 001}$ & CERRO TO & 1815517.158 & .029 & -5213464.875 & .029 & 7999.408 & .029 \\
\hline M001 & ASKITES & 4353444.929 & .021 & 2082666.283 & .021 & 6506.648 & .021 \\
\hline$\underline{\mathrm{M} 001}$ & KATAVIA & 4573400.091 & .022 & 2409322.200 & .021 & 881.751 & .022 \\
\hline$\underline{\mathrm{M} 002}$ & DIONYSOS & 4595216.461 & .020 & 2039435.345 & .021 & 629.488 & .021 \\
\hline M001 & ROUMELLI & 4728694.704 & .018 & 2174373.372 & .018 & 4572.923 & .018 \\
\hline$\underline{\mathrm{M} 002}$ & CAGLIARI & 4893398.119 & .019 & 772673.316 & .019 & 4004140.939 & .020 \\
\hline$\underline{\mathrm{M} 002}$ & BOLOGNE & 4461399.729 & .016 & 919566.848 & .017 & 4449510.490 & .018 \\
\hline S001 & METSAHOV & 2892595.614 & .024 & 1311807.759 & .024 & 5512610.719 & .024 \\
\hline$\underline{S 001}$ & ZIMMERWA & 4331283.630 & .017 & 567549.537 & .017 & 4633139.941 & .017 \\
\hline$\underline{\mathrm{S} 002}$ & WETTZELL & 4075530.090 & .013 & 931781.316 & .013 & 4801618.172 & .014 \\
\hline$\underline{S 001}$ & CERGA GR & 4581691.822 & .015 & 556159.394 & .015 & 4389359.383 & .015 \\
\hline$\underline{\mathbf{S 0 0 1}}$ & SHANGHAI & -2831087.790 & .019 & 4676203.485 & .018 & 3275172.826 & .021 \\
\hline$\underline{S 001}$ & SIMOSATO & -3822388.354 & .018 & 3699363.497 & .017 & 3507573.095 & .019 \\
\hline$\underline{\mathrm{S} 002}$ & LUSTBUEH & 4194426.735 & .017 & 1162693.874 & .017 & 4647246.544 & .017 \\
\hline S001 & HERSTMON & 4033463.849 & .017 & 23662.354 & .017 & 4924305.017 & .017 \\
\hline S007 & CANBERRA & -4446476.781 & .018 & 2678127.080 & .018 & -3696251.774 & .018 \\
\hline$\underline{\mathrm{M} 002}$ & FLAGSTAF & -1923976.627 & .018 & -4850871.713 & .018 & 3658574.856 & .018 \\
\hline M001 & PASADENA & -2493211.862 & .018 & -4655229.531 & .018 & 3565574.503 & .018 \\
\hline S001 & AREQUIPA & 1942792.008 & .018 & -5804077.671 & .018 & -1796919.305 & .018 \\
\hline S001 & MATERA & 4641965.108 & .017 & 1393069.947 & .017 & 4133262.218 & .017 \\
\hline S003 & CANBERRA & -4447548.616 & .018 & 2677133.980 & .018 & -3694996.475 & .019 \\
\hline
\end{tabular}


Table 3. cont.

\begin{tabular}{|ll|rrrrrr|}
\hline & STATION & $X$ & $m_{x}$ & $Y$ & $m_{y}$ & $Z$ & $m_{z}$ \\
& & & & {$[\mathrm{~m}]$} & & & \\
\hline$\underline{\text { S002 }}$ & FORT DAV & -1330781.240 & .010 & -5328755.585 & .011 & 3235697.676 & .011 \\
$\underline{\underline{\text { S005 }}}$ & MAUI I & -5466006.954 & .012 & -2404428.165 & .012 & 2242188.478 & .013 \\
CERGA GR & 4581692.400 & .015 & 556195.867 & .015 & 4389354.945 & .016 \\
\hline
\end{tabular}

\section{References}

BIH, 1986-1989, BIH Annual Reports for 1985, 1986, 1987.

Boucher C., 1987, Definition and Realization of Terrestrial Reference System for Monitoring Earth Rotation. IUGG Symposium No 4. IUGG General Assembly, Vancouver, 1987.

Boucher C., Feissel M., 1984, Realization of the BIH Terrestrial System, Proc of the Intern. Symp. on Space Technique for Geodynamics., Somogyi, Ch. Reigber (eds.) Res. Inst. of Hungarian Acad. of Sci. (Sopron, Hungary)., Vol. I

Boucher C., Altamimi Z., 1985, Towards an Improved Realization of the BIH Terrestrial Reference Frame., Proc. of the Int. Conference on Earth Rotation and the Terrestrial Reference Frame, July 31 - August 2, 1985, Ohio State University, Columbus, Ohio, USA.

Boucher C., Altamimi Z., 1986, The use of space techniques for the connection of geodetic datums., XXVI COSPAR Meeting, Toulouse, France, July 1986.

Boucher C., Altamimi Z., 1986, Status of the Realization of the BIH Terrestrial System., Proc. of the IAU Symposium No 127 "On Earth's Rotation and Reference Frames for Geodesy and Geodynamics., Conf. held in Washington, USA, 20-24 October 1986., Kluwer Acad. Publ.

Boucher C., Altamimi Z., 1987, Intercomparison of VLBI, LLR, SLR and GPS Derived Baselines on a Global Basis, EGS Meeting, Strasburg 1987.

Boucher C., Altamimi Z., 1988, Complement of analysis of BIH Terrestrial System for 1987 ., BIH Annual Report for 1987., Paris, France.

Boucher C., Altamimi Z., 1989, The initial IERS Terrestrial Reference Frame, IERS Technical Note 1. Paris, France.

IERS Annual Report for 1988 and 1989, Paris, France., 1989, 1990.

Kosek W., Kolaczek B., 1990, The optimum conventional terrestrial system determined by VLBI and SLR stations., Proc. of IAU Symposium o 105 on Earth Rotation and Coordinate Reference Frames, Springer Verlag.

Mueller I.I., and Zerbini S. (eds.), 1989., The Interdisciplinary Role of Space Geodesy, Proceedings of an International Workshop held in Erice, Italy, July 23-29, 1988, Springer Verlag. 